\title{
Estudo Comparativo do Acúmulo de Massa Seca e Macronutrientes por Plantas de Milho var. BR-106 e Brachiaria plantaginea
}

\author{
Dry Matter and Macronutrient Accumulation by Maize and Brachiaria plantaginea
}

CARVALHO, L.B. ${ }^{2}$, BIANCO, S. ${ }^{3}$, PITELLI, R.A. ${ }^{4}$ e BIANCO, M.S. ${ }^{5}$

\begin{abstract}
RESUMO - Foram realizados dois experimentos, em casa de vegetação, no Departamento de Biologia Aplicada à Agropecuária da FCAV-UNESP de Jaboticabal, objetivando-se determinar o acúmulo de massa seca e a distribuição e acúmulo de macronutrientes em plantas de milho, no período de outubro de 2000 a fevereiro de 2001, e de capim-marmelada, no período de setembro de 2003 a fevereiro de 2004. Os estudos foram realizados em delineamento experimental inteiramente casualizado, com quatro repetições. As plantas cresceram em vasos com capacidade de sete litros - preenchidos com areia de rio lavada e peneirada - e foram irrigadas diariamente com solução nutritiva. Os tratamentos foram representados pelas épocas de amostragem realizadas a intervalos de 14 dias, a saber: 21, 35, 49, 63, 77, 91, 105, 119 e 133 dias após a emergência (DAE) das plantas de milho; e 21, $35,49,63,77,91,105,119,133$ e 147 DAE das plantas de capim-marmelada. O ponto de máximo acúmulo teórico de massa seca deu-se aos 122 DAE para o milho (143,8 g por planta) e aos 143 DAE para o capim-marmelada (23,9 g por planta). A taxa de absorção diária dos macronutrientes atingiu maiores valores entre 71 e 104 DAE para o milho e entre 96 e 111 DAE para a planta daninha. Levando-se em conta a média dos valores de pontos de inflexão observados na cultura do milho, aos 85 DAE uma planta de milho acumula, teoricamente, 83,0 g de massa seca; 788,9 mg de N; 137,5 mg de P; 1.385,6 mg de K; 551,8 mg de $\mathrm{Ca} ; 217,9 \mathrm{mg}$ de $\mathrm{Mg}$; e $92,5 \mathrm{mg}$ de $\mathrm{S}$. Enquanto que, no mesmo período, uma planta de B. plantaginea acumula, teoricamente, 9,6 g de massa seca; 127,8 mg de N; 15,9 mg de P; 217,3 mg de K; 43,9 mg de Ca; 58,3 mg de Mg; e 15,8 mg de S.
\end{abstract}

Palavras-chave: capim-marmelada, biomassa, nutrição mineral, análise de crescimento.

ABSTRACT - Two trials were conducted under greenhouse conditions at the FCAV/UNESPfacilities in Jaboticabal, SP, Brazil, to determine dry matter accumulation, as well as macronutrient distribution and accumulation in maize plants from October 2000 to February 2001, and in Alexandergrass, a major maize weed, especially in southern Brazil, from September 2003 to February 2004. The trials were arranged in a completely randomized experimental design, with four replicates. The plants were grown in seven-liter pots, filled with sand and irrigated daily with nutrient solution. The treatments consisted of different evaluations taken every 14 days, as follows: at 21, 35, 49, 63, 77, 91, 105, 119 and 133 days after maize plant emergence, and at 21, 35, 49, 63, 77, 91, 105, 119 , 133 and 147 days after Alexandergrass emergence. The maximum theoretical dry matter accumulation point occurred at 122 days after emergence (DAE) for maize plants $(143.8 \mathrm{~g}$ per plant) andat $143 \mathrm{DAE}$ for Alexandergrass (23.9 $\mathrm{g}$ per plant). Daily absorption rate of macronutrients reached the greatest

1 Recebido para publicação em 17.8.2006 e na forma revisada em 15.5.2007.

Parte do trabalho de graduação do primeiro autor apresentado à FCAV/UNESP-Jaboticabal-SP.

2 Mestrando do Programa de Pós-Graduação em Produção Vegetal da FCAV/UNESP, Jaboticabal-SP, <agrolbcarvalho@yahoo.com.br>; ${ }^{3}$ Professor Livre-Docente do Dep. de Biologia Aplicada à Agropecuária, Faculdade de Ciências Agrárias e Veterinárias, Universidade Estadual Paulista, FCAV/UNESP, <sbianco@fcav.unesp.br >; ${ }^{4}$ Professor Titular do Dep. de Biologia Aplicada à Agropecuária, Faculdade de Ciências Agrárias e Veterinárias, Universidade Estadual Paulista, FCAV/UNESP, Via de Acesso Professor Paulo Donato Castellane s/n, 14884-900 Jaboticabal-SP, <rapitelli@ecosafe.agr.br>; ${ }^{5}$ Acadêmico do curso de Agronomia - FCAV/ UNESP, Jaboticabal-SP, <matbianco2004@yahoo.com.br>. 
values between 71 and 104 DAE for maize plants and between 96 and 111 DAE for the weed. Taking into account the average values of the inflexion points observed for maize crops, it is possible to estimate that at 85 DAE one maize plantaccumulates theoretically $83.0 \mathrm{~g}$ of dry matter; $788.9 \mathrm{mg}$ of $\mathrm{N} ; 137.5 \mathrm{mg}$ of $P$; $1385.6 \mathrm{mg}$ of $\mathrm{K} ; 551.8 \mathrm{mg}$ of Ca; $217.9 \mathrm{mg}$ of $\mathrm{Mg}$ and $92.5 \mathrm{mg}$ of $\mathrm{S}$. In the same period, a B. plantaginea plant accumulates theoretically $9.6 \mathrm{~g}$ of dry matter; $127.8 \mathrm{mg}$ of $\mathrm{N} ; 15.9 \mathrm{mg}$ of P; $217.3 \mathrm{mg}$ of $\mathrm{K} ; 43.9 \mathrm{mg}$ of $\mathrm{Ca} ; 58.3 \mathrm{mg}$ of $\mathrm{Mg}$ and $15.8 \mathrm{mg}$ of $\mathrm{S}$.

Keywords: alexandergrass, biomass, mineral nutrition, growth analysis.

\section{INTRODUÇÃO}

No Brasil, a cultura do milho é de grande importância para o agronegócio, além de ser base de sustentação para a pequena propriedade, constituindo um dos principais insumos no complexo agroindustrial.

As plantas daninhas requerem, para seu desenvolvimento, os mesmos fatores exigidos pela cultura do milho, estabelecendo um processo competitivo quando as duas se desenvolvem conjuntamente. A competição por nutrientes essenciais é de grande importância, pois estes, na maioria das vezes, são limitados. As perdas ocasionadas na cultura do milho em razão da interferência imposta pelas plantas daninhas têm sido descritas na ordem de $13,1 \%$; nos casos em que não tenha sido realizado nenhum método de controle, pode chegar a aproximadamente $85 \%$ (Carvalho, 2004).

Dependendo das condições ambientais e da população de plantas daninhas em uma determinada gleba, as perdas ocasionadas pela interferência destas na cultura do milho podem atingir $85 \%$ no sistema de plantio convencional e até $100 \%$ no sistema de plantio direto. O controle das plantas daninhas é, portanto, uma necessidade de ordem econômica e não estética (Silva \& Pires, 1991).

O prejuizo potencial das plantas daninhas em lavouras de milho pode chegar a reduções de até $90 \%$ do rendimento de grãos (Ruedell, 1991). Essa redução é ocasionada principalmente pela competição interespecífica por água, luz e nutrientes (Swanton \& Weise, 1991; Kapusta et al., 1994) e, também, pela competição por dióxido de carbono, espaço físico e temperatura (Anderson, 1977).

Brachiaria plantaginea é uma gramínea de ciclo anual com reprodução por sementes.
Cresce principalmente nos períodos de primavera e verão em áreas ocupadas com culturas anuais, especialmente lavouras de milho e soja (Hafliger \& Scholz, 1980; Kissmann \& Groth, 1999). No Brasil, é uma das plantas daninhas mais freqüentes nos solos cultivados das regiões Centro-Oeste e Sul e está presente em quase todos os Estados (Lorenzi, 1991). Encontra-se em $62 \%$ das áreas do Planalto do Rio Grande do Sul, sendo a gramínea com maior incidência nessa região (Bianchi, 1996). A presença desta planta daninha na lavoura pode reduzir o rendimento de grãos de milho em até 90\% (Merotto Jr. et al., 1997), podendo inviabilizar economicamente o cultivo desta cultura se o manejo for inadequado. Esta planta é pouco conhecida em termos de crescimento, desenvolvimento e exigências nutricionais, não sendo encontradas referências sobre o assunto na literatura consultada.

Alguns estudos foram realizados, visando conhecer as curvas de crescimento e de acúmulo de nutrientes por espécies como Commelina benghalensis (Rodrigues et al., 1995), Senna obtusifolia (Erasmo et al., 1997), Hyptis suaveolens (Gravena et al., 2002), Richardia brasiliensis (Pedrinho Junior et al., 2004) e Rottboelia exaltata (Bianco et al., 2004). Estes estudos, realizados em casa de vegetação, não incluíram uma espécie cultivada, tornando difícil extrapolações comparativas. Assim, neste trabalho, objetivou-se estudar o acúmulo e a distribuição de massa seca e de macronutrientes por plantas de milho e capim-marmelada cultivadas em condições similares, mas não simultâneas, possibilitando comparações.

\section{MATERIAL E MÉTODOS}

Foram realizados dois experimentos em casa de vegetação do Departamento de Biologia 
Aplicada à Agropecuária da Faculdade de Ciências Agrárias e Veterinárias - UNESP de Jaboticabal, no período de outubro de 2000 a fevereiro de 2001 para a cultura do milho e de setembro de 2003 a fevereiro de 2004 para $B$. plantaginea. No primeiro experimento, estudou-se o acúmulo de massa seca, alocação e acúmulo de macronutrientes por plantas de Zea maysvar. BR-106 e, no segundo, por plantas de B. plantaginea, utilizando-se como substrato areia de rio lavada e, como fonte de nutrientes, solução nutritiva completa de Hoagland \& Arnon (1950).

O substrato foi peneirado em tamis de $5 \mathrm{~mm}$ e acondicionado em vasos plásticos com capacidade para sete litros, perfurados e conectados, através de mangueiras plásticas de $1,0 \mathrm{~cm}$ de diâmetro e $75 \mathrm{~cm}$ de comprimento, a frascos de vidro escuro com capacidade de um litro. A finalidade era coletar a solução lixiviada das irrigações e posteriormente retorná-la aos vasos. Foram plantadas 20 sementes por vaso de $Z$. mays e 50 sementes por vaso de $B$. plantaginea. Em ambos os experimentos, quando as mudas atingiram dois pares de folhas verdadeiras totalmente expandidas, foi efetuado desbaste, deixando-se quatro plantas por vaso. Em se tratando da cultura do milho, a partir de 63 dias após a emergência, foi mantida apenas uma planta por vaso.

Os vasos foram irrigados com a solução nutritiva completa de Hoagland \& Arnon (1950), recebendo $25 \%$ da concentração original até a primeira amostragem e, depois, $50 \%$ até o final da fase experimental. Foram realizadas duas irrigações diárias, sendo a primeira no período da manhã e a segunda logo no início do período da tarde, adicionando-se $350 \mathrm{ml}$ da solução. Em dias de temperaturas elevadas, quando necessário, foi realizada uma terceira irrigação ao final da tarde, adicionando $350 \mathrm{ml}$ de água deionizada, evitando dessa forma possivel salinização do substrato e imposição de estresse hídrico às plantas.

Os vasos foram distribuídos aleatoriamente na casa de vegetação e suas posições foram alteradas semanalmente, também de modo aleatório, permitindo assim a casualização das parcelas. O delineamento experimental utilizado foi o inteiramente casualizado, com quatro repetições. Foram utilizadas nove e dez épocas de amostragem para milho e capim- marmelada, respectivamente, devido ao ciclo de desenvolvimento das espécies.

Os tratamentos foram representados pelas épocas de amostragens, realizadas a intervalos de 14 dias, a saber: $21,35,49,63,77,91,105$, 119 e 133 dias após a emergência (DAE) das plantas de milho e $21,35,49,63,77,91,105$, 119, 133 e 147 DAE para o capim-marmelada.

Nas avaliações, as plantas foram separadas em raízes, colmos mais bainhas, folhas e estruturas reprodutivas. Em seguida, esses materiais foram lavados na seguinte seqüência: rápida imersão em solução diluída de detergente neutro, lavagem e imersão em água destilada e, finalmente, imersão em água deionizada.

Após a lavagem, as diferentes partes das plantas foram acondicionadas em sacos de papel devidamente etiquetados e perfurados, para posterior secagem em estufa de circulação forçada de ar, a $60-70{ }^{\circ} \mathrm{C}$, por 96 horas. A determinação da massa seca foi efetuada em balança eletrônica com precisão de $0,001 \mathrm{~g}$. Após a pesagem, o material foi moído em micromoinho tipo Willey, malha 20, armazenado em frascos de vidro hermeticamente fechados e, posteriormente, analisado quanto ao teor de macronutrientes.

A análise de nitrogênio $(\mathrm{N})$ total foi efetuada pelo método do semimicro Kjeldahl, e a do fósforo (P), pelo método do ácido fosfovanadatomolíbdico (Sarruge \& Haag, 1974). A determinação de potássio (K), cálcio (Ca) e magnésio $(\mathrm{Mg})$ foi feita por espectrofotometria de absorção atômica (Jorgensen, 1977), enquanto o enxofre (S) foi determinado pelo método turbidimétrico (Vitti, 1989).

Por meio da observação dos valores encontrados no teor de cada nutriente ao longo do ciclo da planta, foi possivel determinar a amplitude de variação do teor total de cada nutriente; para isso, foram observados o maior e o menor valor de teor total.

Os acúmulos de nutrientes para cada uma das partes da planta foram conseguidos multiplicando-se o teor do nutriente pela massa seca correspondente. $\mathrm{O}$ acúmulo total foi obtido por meio da somatória dos acúmulos das diferentes partes da planta, ao passo que o teor total da planta foi obtido pela relação entre o acúmulo 
total da planta e a massa seca total correspondente.

Para cálculo do acúmulo total teórico dos macronutrientes, utilizou-se a integral sob a equação exponencial ajustada, $\mathrm{Y}=\exp (\mathrm{a}+\mathrm{bx}$ $+\mathrm{cx}^{2}$ ), sendo $\mathrm{Y}=$ acúmulo do nutriente $\mathrm{e} \mathrm{x}=$ dias após a emergência, ajustando-se curvas de crescimento em função dos dias do ciclo de vida da planta, refletindo um esboço comportamental de cada espécie em relação à massa seca e ao nutriente estudado, com o auxílio do programa Statistics (Statsoft, 2001). Na escolha da equação de regressão foram considerados a lógica do fenômeno biológico do crescimento e o valor do coeficiente de determinação. Os pontos de inflexão e de máximo da curva foram determinados pelas derivadas - primeira e segunda da equação ajustada aos dados obtidos -, utilizando o programa MAPLE V (Char et al., 1991).

\section{RESULTADOS E DISCUSSÃO}

Apesar da limitação de que os experimentos foram conduzidos em épocas distintas, para fins de discussão dos resultados, considera-se que o milho foi mais precoce na alocação de recursos para as estruturas reprodutivas (Figura 1). O acúmulo de massa seca pelas estruturas reprodutivas das espécies em estudo foi crescente até o final da fase experimental; o capim-marmelada apresentou baixo florescimento e, conseqüentemente, a alocação de recursos para as suas estruturas reprodutivas foi, também, muito pequena. Ambas as espécies apresentaram acúmulo de massa seca crescente pelas estruturas reprodutivas até o final da fase experimental. O milho acumulou cerca de $50 \%$ de massa seca total, e o capim-marmelada, aproximadamente $6,0 \%$. Esse acúmulo de massa seca nas estruturas reprodutivas do milho é conseqüência do melhoramento genético, em que a produção é uma das principais características buscadas pelo melhorista.

Uma característica interessante do capimmarmelada foi o incremento inicial na alocação de biomassa para o sistema radicular $(60 \%$ aos 35 dias após a emergência), o que melhoraria a fixação da planta ao solo e facilitaria a competição por nutrientes e água.
Também, é importante destacar que, após o início da fase reprodutiva do capim-marmelada, as folhas diminuíram sua participação já a partir dos 77 DAE. Para as raízes, a diminuição na alocação de biomassa seca ocorreu a partir dos 35 DAE. Comportamento semelhante com espécies daninhas também foi relatado por Rodrigues et al. (1995) em Commelina benghalensis; por Erasmo et al. (1997), em Senna obtusifolia; por Gravena et al. (2002), em Hyptis suaveolens; por Pedrinho Junior et al. (2004), em Richardia brasiliensis; e por Bianco et al. (2004), em Rottboelia exaltata.

A Figura 2 mostra as diferenças nos teores de macronutrientes das plantas de milho e capim-marmelada. As amplitudes dos valores das concentrações dos nutrientes avaliados durante o ciclo das plantas foram maiores no milho, para fósforo e cálcio. As amplitudes para nitrogênio, potássio, magnésio e enxofre foram maiores para o capim-marmelada. Assim, por unidade de biomassa acumulada, o capim-marmelada foi eficiente no recrutamento de nitrogênio, potássio, magnésio e enxofre, e o milho, no de fósforo e cálcio.

Quanto ao acúmulo de massa seca (Figura 3) e de macronutrientes (Figuras 4 a 9) para as duas espécies, o comportamento foi semelhante dentro de cada espécie e diferente entre as espécies, tendo pontos de máximo acúmulo variando entre 101 e 138 DAE para a cultura do milho e de 128 a 163 DAE para a espécie daninha. Os pontos de inflexão ficaram em torno de 71 a 104 DAE para a cultura do milho e de 96 a 110 DAE para a planta daninha. A discrepância entre os valores observados para cada espécie é notada em todos os macronutrientes analisados, mas é explicável se forem observados os pontos de máximo acúmulo de massa seca e o ciclo das duas plantas estudadas.

O acúmulo máximo de massa seca total na cultura do milho ocorreu aos 122 DAE, com o valor teórico de 143,77 g de massa seca por planta. Esse valor é superior aos obtidos por Andrade et al. (1975a, b), que encontraram em condições de campo o máximo acúmulo de massa seca para cinco cultivares de milho entre 100 e 110 dias -, que caracteriza o período de maturação fisiológica da espécie. Para $B$. plantaginea, ocorreu aos $143 \mathrm{DAE}$, com o valor teórico de 23,87 g de massa seca por planta 

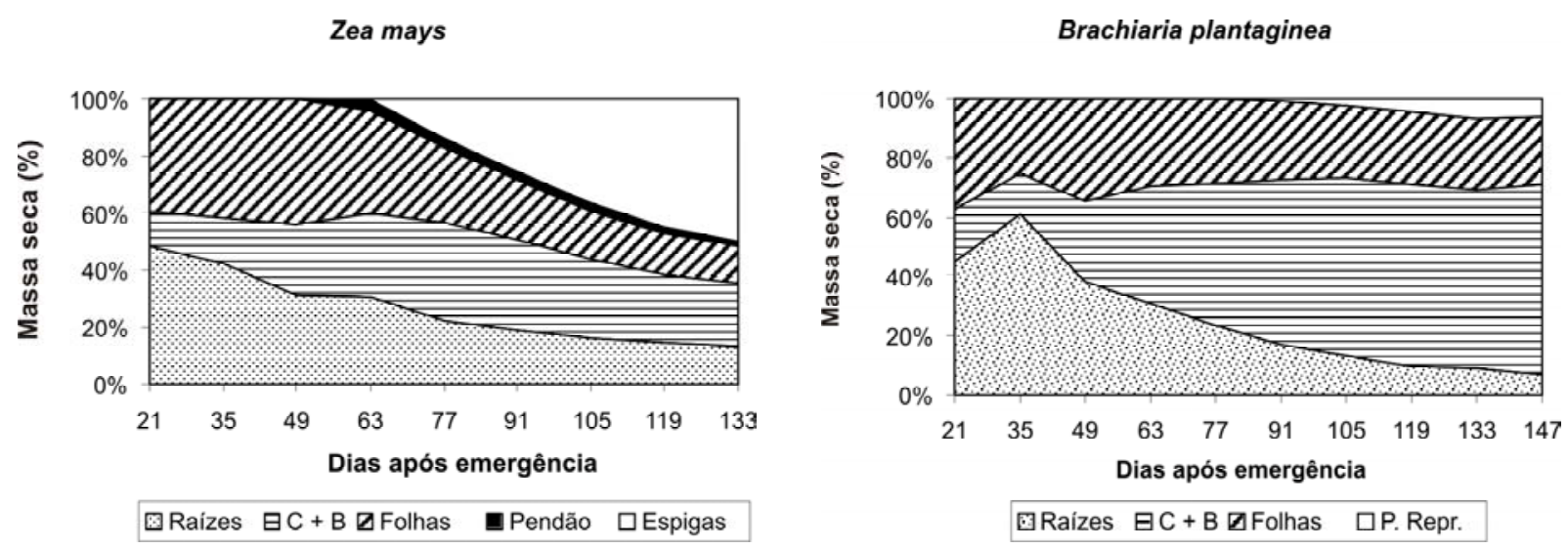

Figura 1 - Distribuição percentual da massa seca acumulada nas diferentes partes das plantas de milho e capim-marmelada, ao longo dos seus ciclos de desenvolvimento. Jaboticabal-SP, 2005.

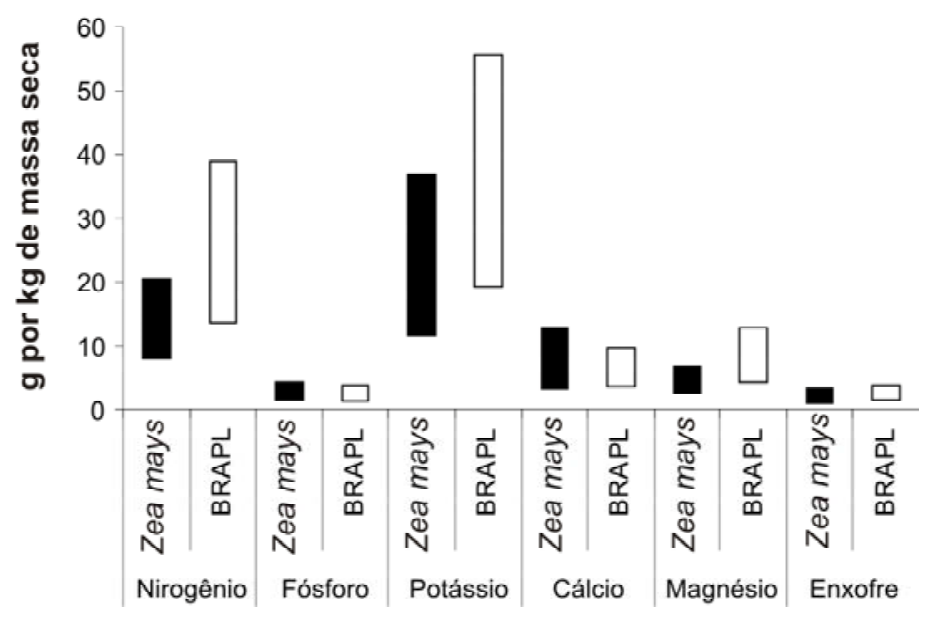

Figura 2 - Amplitude da variação dos teores totais de nitrogênio, fósforo, potássio, cálcio, magnésio e enxofre nas plantas de milho e capim-marmelada, quando cultivadas em areia de rio lavada e irrigadas com solução nutritiva. Jaboticabal-SP, 2005.

(Figura 3). Este valor é inferior aos encontrados para outras plantas daninhas, como Hyptis suaveolens (Gravena et al., 2002), Senna obtusifolia (Erasmo et al., 1997) e Richardia brasiliensis (Pedrinho Junior et al., 2004), quando considerado o período em que estas podem conviver com a cultura (0-147 DAE).

O valor do ponto de inflexão pode ser entendido como o dia em que o acúmulo diário dos macronutrientes da planta chegou ao seu valor máximo, sendo a taxa de absorção diária crescente até esse momento. Para as plantas de milho, os valores obtidos foram: 88, 104, 76,
71, 84 e 84 DAE, e para o capim-marmelada: 100, 99, 110, 96, 97 e $100 \mathrm{DAE}$, para N, P, K Ca, $\mathrm{Mg}$ e S, respectivamente. Huett \& Dettman (1988) e Fayad et al. (2002) utilizaram o mesmo parâmetro para determinar o máximo acúmulo diário de macronutrientes em tomateiros, sendo relatado pelos últimos autores 46, 39, 51, 45, 15 e 44 dias após o transplante das mudas, para $\mathrm{N}, \mathrm{P}, \mathrm{K}, \mathrm{Ca}, \mathrm{Mg}$ e $\mathrm{S}$, respectivamente.

É possivel que as diferenças na taxa de absorção de um nutriente ao longo do ciclo de vida da planta sejam reguladas por um controle no tipo ou na atividade do transportador. Como 


\section{Zea mays}

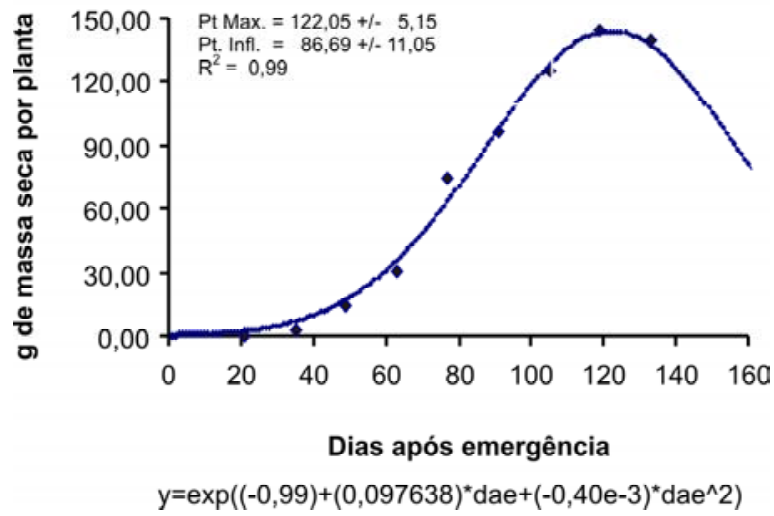

\section{Brachiaria plantaginea}

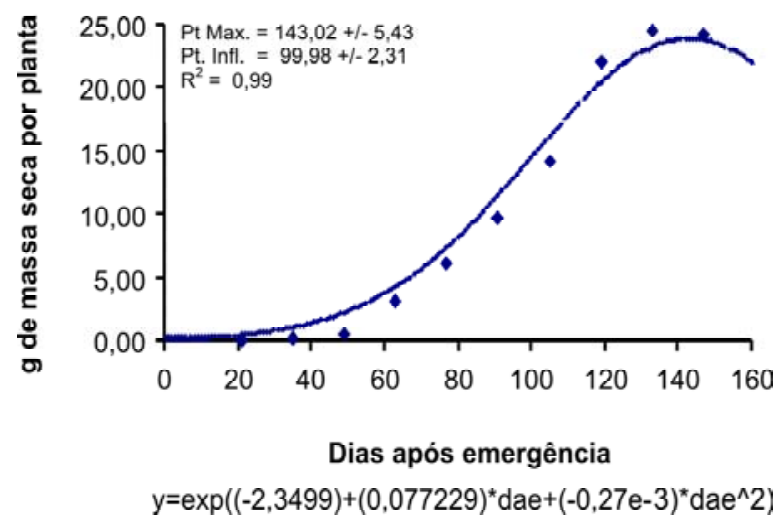

Figura 3 - Curvas de acúmulo de massa seca total, equação ajustada, respectivos pontos de máximo e de inflexão (DAE) e mais ou menos o desvio-padrão dos pontos estudados nas quatro repetições. Jaboticabal-SP, 2005.

Zea mays

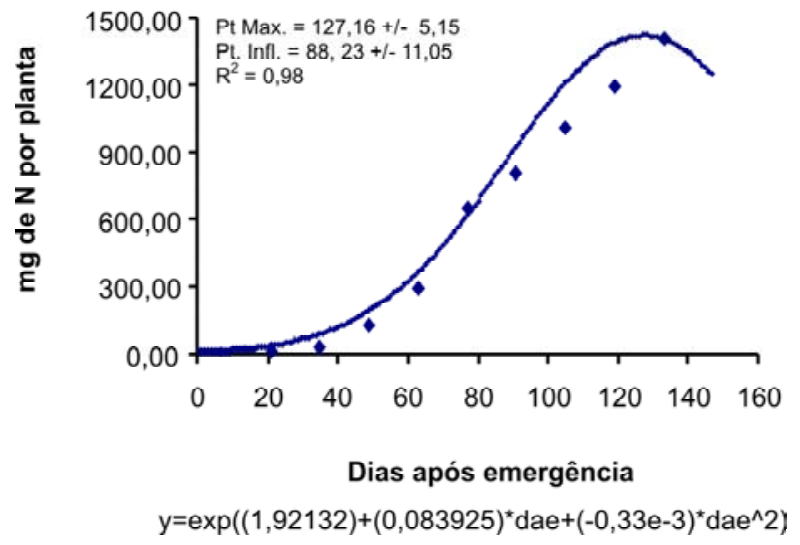

Brachiaria plantaginea

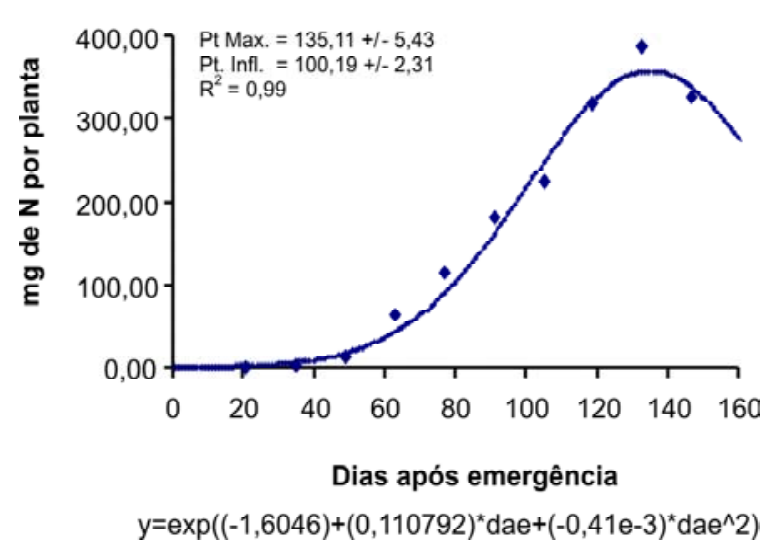

Figura 4 - Curvas de acúmulo de nitrogênio total, equação ajustada, respectivos pontos de máximo e de inflexão (DAE) e mais ou menos o desvio-padrão dos pontos estudados nas quatro repetições. Jaboticabal-SP, 2005.

exemplo, o transporte ativo de $\mathrm{K}^{+}$ocorre quando ele está em concentrações externas muito pequenas, e o passivo (de baixa afinidade), quando há altas concentrações desse elemento (Peres, 2003). O tipo de transporte e a disponibilidade dos nutrientes no meio influenciam diretamente a taxa de absorção do elemento, a qual por sua vez afetará o acúmulo deste, pois somente podem ser observados altos valores de acúmulo de um dado nutriente quando, antecipadamente, houver alta absorção dele.

De modo geral, o máximo acúmulo diário dos nutrientes coincidiu com o período inicial de frutificação de ambas as espécies, como também observado por Fayad et al. (2002) em tomateiros. Nesse período ocorre o estabelecimento de uma força mobilizadora de nutrientes e assimilados, devido ao aumento da atividade metabólica, associada à atividade hormonal e à divisão e crescimento celular (Taiz \& Zeiger, 1995).

Levando-se em conta a média dos valores de pontos de inflexão observados na cultura do milho (Figuras 4 a 9), aos 85 DAE (ponto de inflexão médio do milho para todos os macronutrientes estudados) uma planta de milho acumula teoricamente $83,0 \mathrm{~g}$ de massa seca; 788,9 $\mathrm{mg}$ de $\mathrm{N} ; 137,5 \mathrm{mg}$ de $\mathrm{P} ; 1.385,6 \mathrm{mg}$ de 


\section{Zea mays}

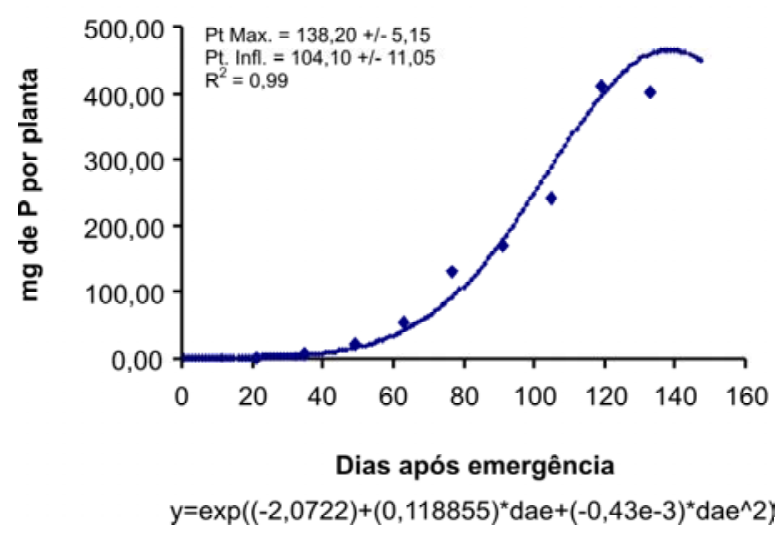

Brachiaria plantaginea

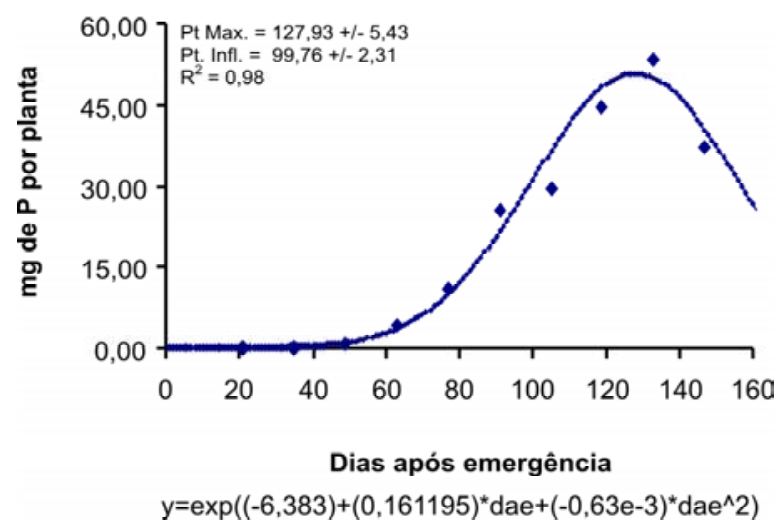

Figura 5 - Curvas de acúmulo total de fósforo, equação ajustada, respectivos pontos de máxima e de inflexão (DAE) e mais ou menos o desvio-padrão dos pontos estudados nas quatro repetições. Jaboticabal-SP, 2005.

\section{Zea mays}

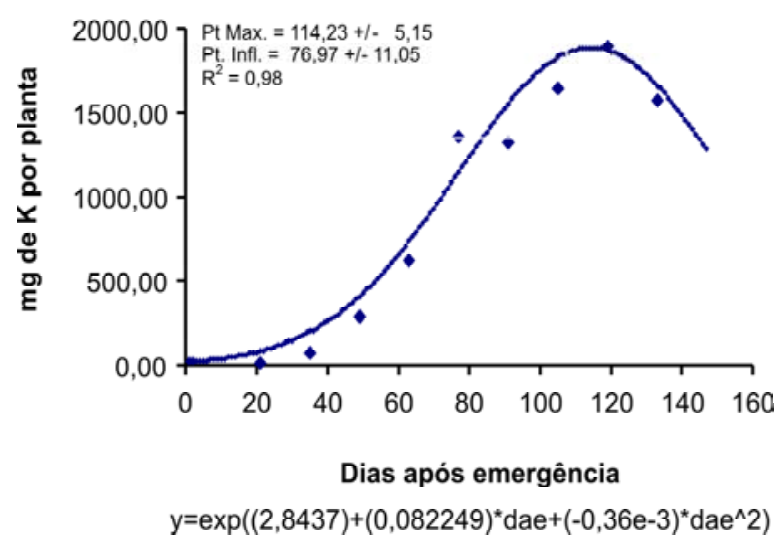

Brachiaria plantaginea

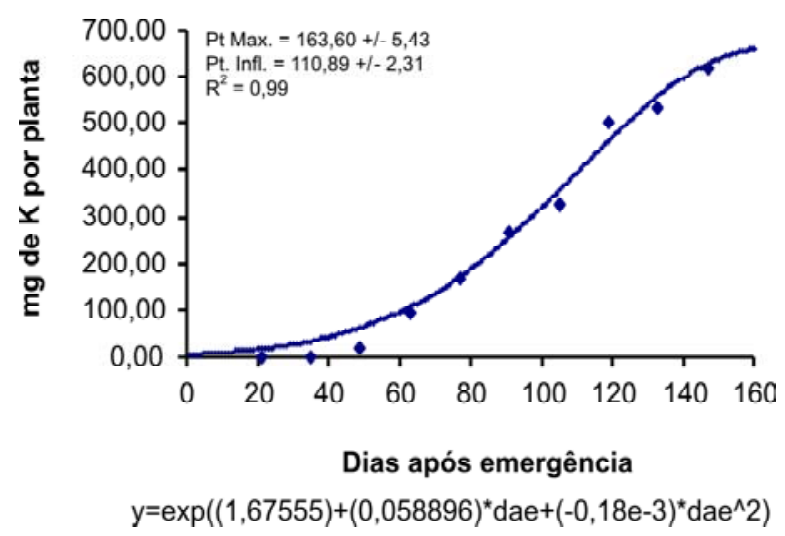

Figura 6 - Curvas de acúmulo total de potássio, equação ajustada, respectivos pontos de máxima e de inflexão (DAE) e mais ou menos o desvio-padrão dos pontos estudados nas quatro repetições. Jaboticabal-SP, 2005.

$\mathrm{K} ; 551,8 \mathrm{mg}$ de Ca; 217,9 mg de Mg; e 92,5 mg de S. Enquanto isso, para o mesmo periodo, uma planta de $B$. plantaginea acumula teoricamente $9,6 \mathrm{~g}$ de massa seca; $127,8 \mathrm{mg}$ de $\mathrm{N} ; 15,9 \mathrm{mg}$ de P; 217,3 mg de K; 43,9 mg de $\mathrm{Ca} ; 58,3 \mathrm{mg}$ de $\mathrm{Mg}$; e 15,8 mg de $\mathrm{S}-$ como se pode observar nas Figuras 4, 5, 6, 7, 8, 9 e 10.

Com base nas observações feitas durante os ensaios e nos dados apresentados, é possivel concluir que as espécies estudadas apresentaram taxa de acúmulo diário dos macronutrientes próximas, com seus maiores valores variando de 71 a 104 DAE para o milho e 96 a 110 DAE para o capim-marmelada.Considerando a média dos valores de pontos de inflexão observados para o milho, aos 85 DAE ele acumula mais massa seca e nutrientes do que a planta daninha, no mesmo período. No entanto, o capim-marmelada poderá prejudicar muito a cultura do milho em termos de competição por macronutrientes, pois ele apresenta seus pontos médios de inflexão ao redor de $100 \mathrm{DAE}$, período em que a planta de milho começa a entrar em seu estágio de maturação fisiológica, coincidindo com o período de elevada taxa de absorção dos macronutrientes pelas plantas, o que poderá acarretar sérios prejuízos à produção final do milho. 


\section{Zea mays}

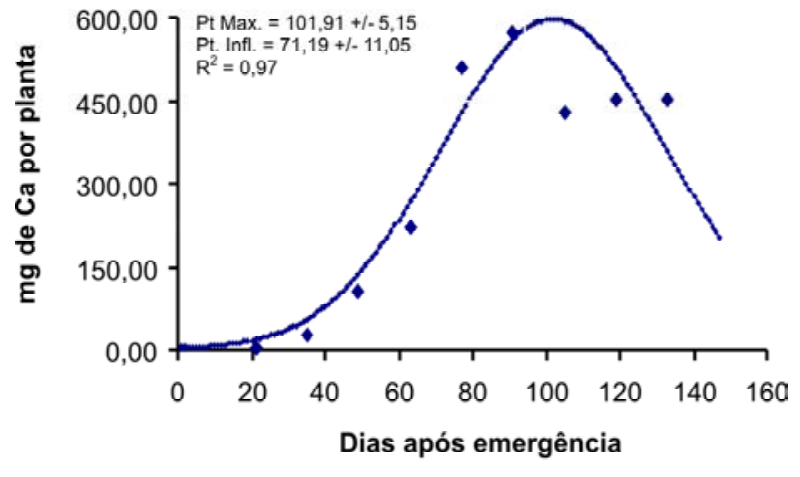

$y=\exp \left((0,885275)+(0,108023)^{*} d a e+(-0,53 e-3)^{\star} d a e^{\wedge} 2\right)$

\section{Brachiaria plantaginea}

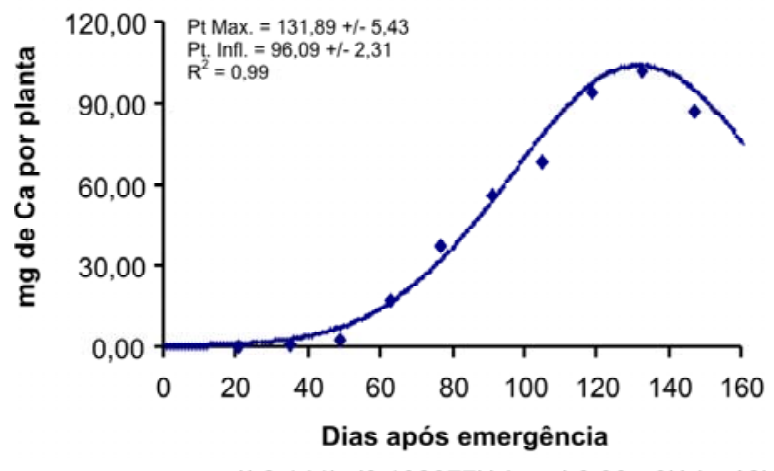

$y=\exp \left((-2,144)+(0,102877)^{\star} d a e+(-0,39 e-3)^{\star} d a e^{\wedge} 2\right)$

Figura 7 - Curvas de acúmulo total de cálcio, equação ajustada, respectivos pontos de máximo e de inflexão (DAE) e mais ou menos o desvio-padrão dos pontos estudados nas quatro repetições. Jaboticabal-SP, 2005.

\section{Zea mays}

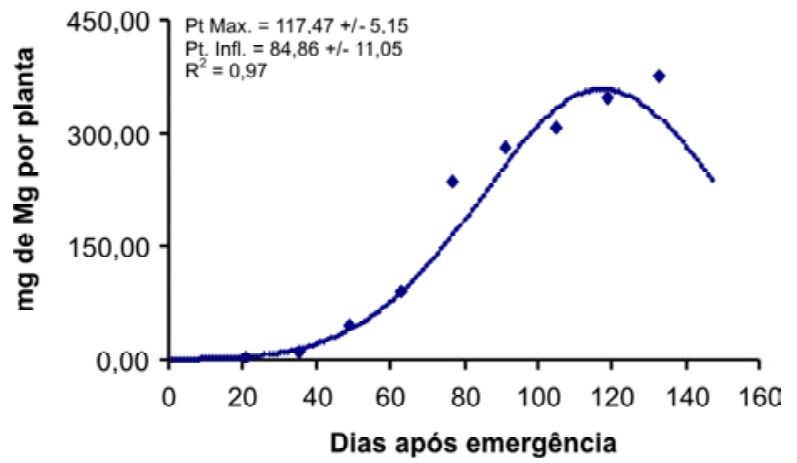

$y=\exp \left((-0,60639)+(0,110427)^{\star} d a e+(-0,47 e-3)^{\star} d a e^{\wedge} 2\right)$

\section{Brachiaria plantaginea}

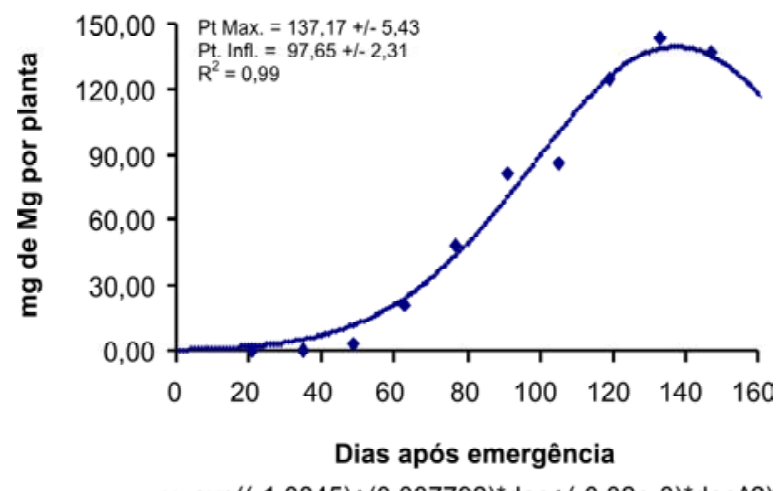

$y=\exp \left((-1,0845)+(0,087792)^{\star}\right.$ dae $\left.+(-0,32 e-3)^{\star} d a e^{\wedge} 2\right)$

Figura 8-Curvas de acúmulo total de magnésio, equação ajustada, respectivos pontos de máximo e de inflexão (DAE) e mais ou menos o desvio-padrão dos pontos estudados nas quatro repetições. Jaboticabal-SP, 2005.

\section{Zea mays}

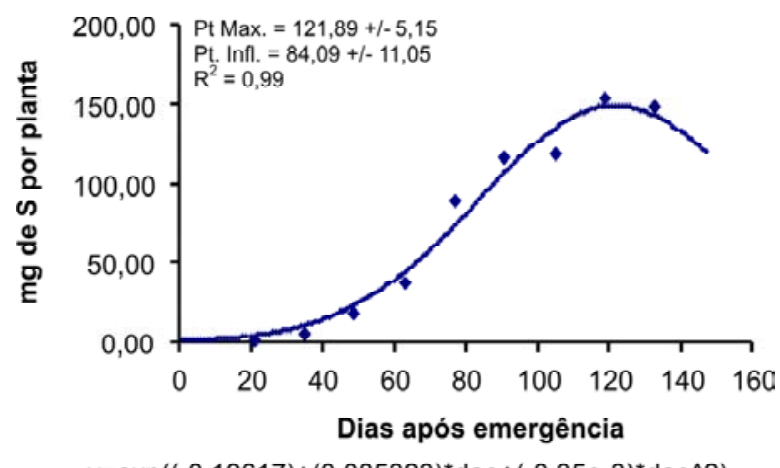

$y=\exp \left((-0,19617)+(0,085323)^{\star}\right.$ dae $+(-0,35 e-3)^{\star}$ dae $\left.{ }^{\wedge} 2\right)$

\section{Brachiaria plantaginea}

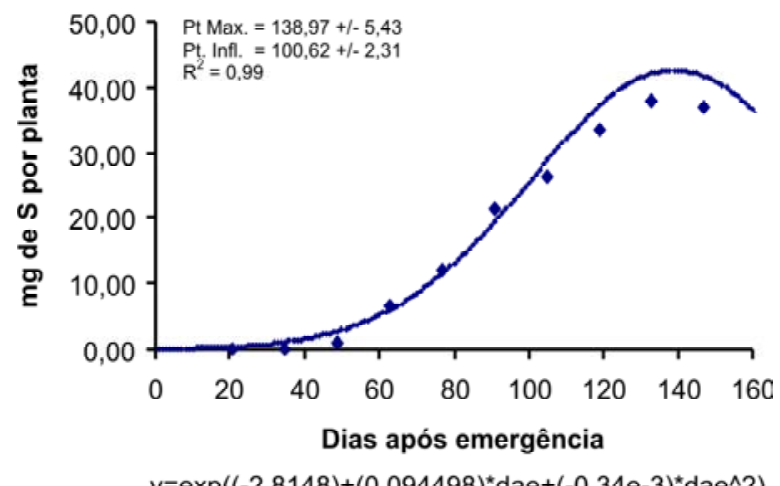

$y=\exp \left((-2,8148)+(0,094498)^{\star} d a e+(-0,34 e-3)^{\star} d a e^{\wedge} 2\right)$

Figura 9 - Curvas de acúmulo total de enxofre, equação ajustada, respectivos pontos de máximo e de inflexão (DAE) e mais ou menos o desvio-padrão dos pontos estudados nas quatro repetições. Jaboticabal-SP, 2005. 


\section{LITERATURA CITADA}

ANDERSON, W. P. Weed Science: principles. 2. ed. St. Paul: West Publishing, 1977. 64 p.

ANDRADE, A. G.; HAAG, H. P.; OLIVEIRA, G. D. Acumulação diferencial de nutrientes por cinco cultivares de milho (Zea mays L.). I. Acumulação de macronutrientes. An. ESALQ, n. 32, p. 115-149, 1975a.

ANDRADE, A. G.; HAAG H. P.; OLIVEIRA, G. D. Acumulação diferencial de nutrientes por cinco cultivares de milho (Zea mays L.). I. Acumulação de micronutrientes. An. ESALQ, n. 32, p. 150-172, 1975 b.

BIANCO, S.; BARBOSA JÚNIOR, A. F.; PITELLI, R. A. Crescimento e nutrição mineral de capim-camalote. Planta Daninha, v. 22, n. 3, p. 375-380, 2004.

BIANCHI, M. A. Programa de difusão de manejo integrado de plantas daninhas em soja. In: REUNIÃO DE PEQUISA DE SOJA DA REGIÃO SUL, 23., 1996, Porto Alegre. Ata e Resumos. Porto Alegre: Universidade Federal do Rio Grande do Sul, 1996. p. 125.

CARVALHO, L. B. Estudo comparativo do acúmulo de massa seca e de macronutrientes por plantas de milho var. Br-106 e capim-marmelada. 2004. $77 \mathrm{f}$. Monografia (Trabalho de Graduação em Agronomia) - Universidade Estadual Paulista, Jaboticabal, 2004.

CHAR, B. W. et al. Maple V, language reference manual. New York: Springer-Verlag, 1991. 411 p.

ERASMO, E. A. L.; BIANCO, S.; PITELLI, R. A. Estudo sobre o crescimento de fedegoso. Planta Daninha, v. 15, n. 2, p. 170-179, 1997.

FAYAD, J. A. et al. Absorção de nutrientes pelo tomateiro cultivado sob condições de campo e de ambiente protegido. Hort. Bras., v. 20, p. 90-94, 2002.

GRAVENA, R. et al. Análise de crescimento de Hyptis suaveolens. Planta Daninha, v. 20, n. 2, p. 189-196, 2002.

HAFLIGER, E.; SCHOLZ, H. Grass weeds 1: weeds of subfamily Panioidea. Basel, Ciba Geigy, 1980. 142 p.

HOAGLAND, D. R.; ARNON, D. J. The water culture method of growing plants without soil. Berkeley: 1950. (Calif. Agric. Exp. Station, 347)

HUETT, D. O.; DETTMAN, B. Effect of $\mathrm{N}$ on growth, fruit quality and nutrient uptake of tomatoes grown in sand culture. Aust. J. Exp. Agric., v. 28, p. 391-399, 1988.
JORGENSEN, S. S. Metodologia utilizada para análise química de rotina: guia analítico. Piracicaba: CENA, 1977. $24 \mathrm{p}$.

KAPUSTA, G. et al. Effect of nicosulfuron rate, adjuvant, and weed size on annual weed control in corn (Zea mays). Weed Technol., v. 8, p. 696-702, 1994.

KISSMANN, K. G.; GROTH, D. Plantas infestantes e nocivas. 2. ed. São Paulo: BASF, 1999. Tomo 3. 978 p.

LORENZI, H. Plantas daninhas do Brasil: terrestres, aquáticas, parasitas, tóxicas e medicinais. 2. ed. Nova Odessa: Plantarum, 1991. 340 p.

MEROTTO JR., A. et al. Aumento da população de plantas e uso de herbicidas no controle de plantas daninhas em milho. Planta Daninha, v. 15, n. 2, p. 141-11, 1997.

PEDRINHO JUNIOR, A. A. F.; BIANCO, S.; PITELLI, R. A. Acúmulo de massa seca e macronutrientes por plantas de Glycine max e Richardia brasiliensis. Planta Daninha, v. 22, n. 1, p. 53-61, 2004.

PERES, L. E. P. Nutrição mineral de plantas. Piracicaba: Escola Superior de Agricultura Luiz de Queiroz, 2003. 30 p. (Apostila de aula)

RODRIGUES, B.N.; PITELLI, R. A.; BELLINGIELI, P. A. Efeitos da calagem do solo no crescimento inicial e absorção de macronutrientes por plantas de trapoeraba (Commelina benghalensis). Planta Daninha, v. 13, n. 2, p. 59-68, 1995.

RUEDELL, J. Cultura do milho. Indicações técnicas para o Rio Grande do Sul. Cruz Alta: Fundacep-Fecotrigo, 1991. $102 \mathrm{p}$.

SARRUGE, J. R.; HAAG, H. P. Análises químicas em plantas. Piracicaba: ESALQ/USP, 1974. 56 p.

SILVA, J. B.; PIRES, N. M. Controle de plantas daninhas na cultura do milho. Inf. Agropec., v. 8, p. 17-21, 1991.

STATSOFT, INC. STATISTIC. Data analysis software system. Version 6. Disponible em: $<$ http:// www.statsoft.com>. Acesso em: 2001.

SWANTON, C. J.; WEISE, S. F. Integrated weed management: the rationale and approach. Weed Technol., v. 5 , n. 3, p. 657-663, 1991.

TAIZ, L.; ZEIGER, E. Plant physiology. California, The Benjamin/Cummings Publishing, 1995. 559 p.

VITTI, G. C. Avaliação e interpretação do enxofre no solo e na planta. Jaboticabal: FUNEP, 1989. 37 p. 